\title{
Pure versus Hybrid Competitive Strategies in the Airport Industry
}

\author{
M.Mahdi Tavalaei (University of Surrey, UK) \\ Juan Santalo (IE Business School, Madrid, Spain) \\ Forthcoming in Transportation Research Part A: Policy and Practice
}

\begin{abstract}
The advent of low-cost carriers has dramatically changed the competitive landscape of the airport industry and diminished the monopoly power that airports once enjoyed. Today, major airports compete directly with periphery airports, which are becoming the apparent choice of low-cost carriers. In fact, contracting with low-cost airlines has become a determinant factor in airport strategies, and airports now face a strategic decision to position themselves towards either lowcost or full-service (legacy) airline, or both. This paper examines the impact of these competitive strategies on airport financial performance. Building on the strategic purity premise, we hypothesise that being either a low-cost-oriented or legacy-oriented airport (pursuing a pure strategy) is associated with superior financial performance, in comparison with combining the two (a hybrid strategy). Moreover, the benefit of pure strategies increases with the intensity of competition among nearby airports. The paper supports these hypotheses with findings drawn from the U.S. airport industry.
\end{abstract}

Keywords: airport competition; competitive strategies; pure strategies; low-cost carriers; fullservice carriers

\section{Introduction}

After enjoying decades of monopoly power, airports are experiencing an increasingly competitive environment. Deregulation of aviation, the advent of low-cost carriers (LCCs), and 
commercialisation and privatisation of airports are among the main factors that have reformed the competitive dynamics in the airport industry (Barret, 2000; Littlechild, 2018; Starkie, 2002). Airports compete for passengers and airlines through different channels. For instance, they may compete locally with adjacent airports - with overlapping catchment areas - or compete more broadly with distant airports in destination markets. They may also compete for connecting traffic or in non-aviation markets (Forsyth, 2006; Fröhlich and Niemeier, 2011). In particular, the rise of LCCs has enabled smaller airports to compete with major and established airports and revolutionised the market, the way airports make contracts with airlines, how they define their customer segment, and how they compete with each other (Francis, Humphreys, and Ison, 2004). Yet, apart from a few studies (e.g. Barrett, 2000; Gillen and Morrison, 2003; Fröhlich and Niemeier, 2011; Pels, Nijkamp, and Rietveld, 2003), the topic of airport competition has remained relatively unexplored. As Graham (2013) stresses, despite the significance of LCCs' emergence, their impact on airport-airline relationships and airports' competitive strategies is an overlooked topic in academic studies, despite being of much relevance not only for scholars but also for managers and policy makers.

This paper is an attempt to respond to these shortcomings from a competitive strategy perspective. It has been well established in the competitive strategy literature that firms with pure strategy outperform those that apply hybrid strategies (e.g. Campbell-Hunt, 2000; Parnell, 1997, 2006; Salavou, 2015). This literature goes back to Porter's theory of competitive advantage, and it shows that mixing the cost leadership and differentiation strategies will result in poorer performance, compared to the pursuit of either of those generic strategies (Porter, 1980, 1985). We apply this strategic purity premise (Thornhill and White, 2007) in the context of the airport industry. 
With the growing prevalence of LCCs and their substantial impact on competition in the airport industry, two distinguishable types of airports have emerged one oriented to attract LCCs, and the other specialised in serving legacy or major airlines. De Neufville (2008) calls these types "low-cost" and "legacy" airports, respectively, and notes that each is associated with certain difficult-to-combine or mutually exclusive requirements. Building on the above-mentioned strategic purity premise, we theorise that the airports that apply either of these pure competitive strategies have higher financial performance than the airports that use hybrid strategies (i.e. those that are "stuck in the middle" [Porter, 1980] and combine the two strategies). Moreover, when facing direct competition with an adjacent airport, it is imperative that airports take a clear competitive position-failing to do so results in even poorer performance. Accordingly, we, hypothesise that the stiffer the competition among airports, the more beneficial (detrimental) it is to apply pure (hybrid) strategies. We test our hypotheses in the U.S. airport industry and find robust and supportive results.

This paper contributes to literature on both competitive strategy and the airport industry in several ways. In particular, the paper's second hypothesis is an expansion of the strategic purity premise. Although there are numerous studies on strategic purity in different sectors (e.g. see Salavou [2015], for a recent review), very few have examined the pertinent contingencies under which pure strategies should outperform hybrid strategies. (e.g. Hill, 1988; Shinkle, Kriauciunas, and Hundley, 2013). For example, Shinkle and colleagues (2013) show that pure strategies are more beneficial in market-oriented environments, compared to an institutional environment with a low degree of market orientation. Our study clearly contributes to this stream of research by showing that the competitive advantage (and hence, superior financial performance) obtained as a result of strategic purity is more profound in more competitive markets. More broadly, our paper 
is among nascent studies (e.g. Barrett, 2000; Gillen and Morrison, 2003; Fröhlich and Niemeier, 2011; Starkie, 2002) on airport competition and how that competition is affected by the growth of low-cost airlines. Notably, Lei and Papatheodorou (2010) call for further studies concerning the effects of LCCs on airport financial performance, and our paper directly responds to this (see Zuidberg, 2017, as a scarce example). Finally, in light of airports' increasing involvement with private third parties (in various business aspects) and pressure from the highly competitive airline sector, even non-privatised airport managers must act in a more businesslike and market-oriented manner, which makes strategic positioning crucial. Showing evidence in favor of strategic purity premise in the airport industry can provide insights for airport managers concerned about their firms' profitability in this increasingly competitive industry.

In the remainder of this paper, we first briefly review the rise in airport rivalry as a result of LCCs' emergence (section 2.1), and the literature on competitive strategy (section 2.2.). Next, we develop our hypotheses about airports' competitive strategies in relation to low-cost or fullservice carriers (section 2.3). After introducing the sample and methodology behind our study in section 3, we test our hypotheses in the U.S. airport industry and provide the findings and robustness tests in section 4 . We conclude the paper in section 5 , by discussing the implications of our findings, the paper's limitations, and our suggestions for further research.

\section{Theoretical background and hypotheses}

\subsection{Impact of low-cost carriers on airport competition}

The advent of LCCs induced a dramatic reform in airports' competitive dynamics. Before the emergence of LCCs, secondary or regional (periphery) airports could, at best, act as feeder points or wait for some seasonal charter traffic. However, with the appearance of LCCs, these isolated 
airports began competing with the main (hub) airports (De Neufville, 2008). As a result of contracting with LCCs, periphery airports have experienced a sizeable rise in passenger traffic and stolen market share from nearby hub airports (Barret, 2000, 2004; Graham 2013).

The typical LCC business model is built upon simplicity and cost efficiency in both product and process (Gillen and Morrison, 2003); the former is reflected in providing "no-frills" flights (i.e. only basic service to the passengers) and the latter in seeking minimal aeronautical charges and other operational costs (Francis et al., 2003), high utilisation of aircraft (Pitt and Brown, 2001), and shorter periods between arrivals and next departures (i.e. turnaround times) (Gillen and Gados, 2008; Graham, 2013).

While product cost saving—namely, by "unbundling" some of the flight services (such as in-flight food and baggage) — is the more apparent part of the LCC business model, the essential source of cost reduction for these airlines lies in process cost savings, such as on landing fees and other aeronautical charges for using airports facilities, and efficiency in utilising the aircraft and crew (Gillen and Gados, 2008). Therefore, choice of airports is a critical decision for LCCs. Periphery airports are the ideal option for these airlines because they offer low congestion and excess capacity; less expensive facilities and services; and lower aeronautical charges in exchange for growth in traffic. However, these advantages are not restricted to the small and periphery airports; the hub and major airports can also provide similar benefits to LCCs.

As Graham (2013) points out, the real picture is more complicated than simply assuming periphery airports can best serve LCCs. On the contrary, a wide range of airports, including medium and large primary ones, are chosed by LCCs worldwide (Dobruszkes, 2006; Dobruszkes, Givoni, and Vowles, 2016; Graham and Dennis, 2007). Studies have even reported a very high 
market share of LCCs at the largest U.S. airports (Abda, Belobaba, and Swelbar, 2012). This trend has opened up competition among various types of airports with different sizes and business models. Today, a main concern among airports is how to serve both LCCs and/or full-service carriers (FSCs). The decision to orient an airport towards serving LCCs or FSCs is now considered a competitive strategy of the airports (Gillen and Lall, 2004; Gillen and Morrison, 2003). As we discuss, this strategic decision significantly affects airport performance.

\subsection{Strategic purity premise}

A renowned premise in competitive strategy literature argues that firms pursuing a pure strategy outperform those that apply mixed or hybrid strategies (see Campbell-Hunt [2000] for a metaanalysis). In his seminal studies, Porter (1980, 1985) argues that firms should apply either differentiation or cost leadership strategy; combining these two generic strategies leads to the socalled "stuck-in-the-middle" situation, which ultimately results in inferior performance. Though Porter's generic strategy is perhaps the best-known typology, a few others exist (e.g. the defender, prospector, and analyser strategies suggested by Miles and Snow [1978]). In any case, the superiority of pure strategy compared to hybrid or "confused" strategy (Wright, 1987) has received widespread, though not universal, support from numerous studies (e.g. Campbell-Hunt, 2000; Dess and Davis, 1984; Hambrick, 1981, 1982; Hawes and Crittenden, 1984; Salavou and Halikias, 2009).

The main theoretical benefits of the strategic purity are clarifying positioning, preventing confusion and complexity, and avoiding mutually exclusive trade-offs (Shinkle et al., 2013; Thornhill and White, 2007). First, hybrid strategies do not allow firms to a take a clear position in the market, and thus expose them to rivalry from two angles (i.e. competitors in cost leadership 
and competitors in differentiation strategies) (Miles and Snow, 1978; Treacy and Wiersema, 1995). Second, due to their inherent complications, hybrid strategies may cause confusion, more complex managerial decisions, and higher costs of implication. Third, hybrid strategies may require their proponents to pursue different sets of activates that are mutually exclusive, as each strategy requires a distinct combination of resources, capabilities, and organisational structures and combining them may cause contradiction and conflict.

As noted, widespread support for the strategic purity premise, especially in accordance with Porter's generic strategies, can be seen in a broad range of industries such as shipping, banking, and hospital services (see Salavou [2015] for a recent review). Nevertheless, some research criticises this view and notes that hybrid strategies can be more appropriate in specific configurations (e.g. Hill, 1988; Murray, 1988)—for instance, in hypercompetitive environments (Gopalakrishna and Subramanian, 2001; Proff, 2000) or transition economies (Manev et al., 2015; Shinkle et al., 2013). After all, we believe that the core logic in favour of pure strategy is that each of the low-cost or differentiation strategies requires specific resources and organisational practices (Allen and Helms, 2006) which are mutually exclusive or at least hard to combine. Hence, it is imperative for the firm to employ one of the pure strategies, and not to mix them together. In line with this claim, we next investigate how strategic purity premise applies in the airport industry, concerning an airport's inclination towards LCCs or FSCs.

\subsection{Strategic purity in the airport industry}

As the growth of LCCs has revolutionised competition in the airport industry, airports must now make decisions for dealing with LCCs and FSCs. Each type of carrier has a distinct business model and imposes different demands on airports, meaning that an airport's relationship with LCCs and 
FSCs is, in fact, a strategic decision (Gillen and Lall, 2004). For instance, LCCs require low airport charges, simple charging structures, quick turnaround times, swift check-in systems, and efficient local transportation (e.g. Barrett, 2004; Graham 2013). Many LCCs ask for aircraft parking stands just beside the terminals for embarking passengers in order to drop the cost of air bridges, and a simple terminal without extensive baggage, check-in, or business lounge services (Francis et al., 2004). According to Barret's (2004) interview with a chief executive at Ryanair, LCCs need "single-story" terminals, a requirement which is reflected in the simple structure of the Ryanair terminal at London Stansted Airport or the JetBlue terminal at Los Angeles' Long Beach Airport. In contrast, the expensive and multi-purpose Terminal 5 at London's Heathrow Airport cost roughly US $\$ 10$ billion, with annual amortisation and operation expenses of US $\$ 30$ dollars per passenger (De Neufville, 2008).

Meeting the different needs of LCCs or FSCs leads to distinct and hard-to-reconcile strategic decisions, operations, and tactics, many of which require particular infrastructure and irreversible investments that can be categorised as sunk costs. Additionally, regarding pricing policies, airports must offer low landing fees and other charges in order to attract LCCs, and then compensate for this discount with a high volume of traffic. However, if the airport is already serving an FSC, changing may result in a conflict of interests or pressure from the incumbent to lower charges (i.e. as low as those that the new LCCs enjoy), which in turn diminishes the aeronautical revenue and may not be recouped by revenue generated from LCCs' high traffic (Humphreys, Ison, and Francis, 2006).

Importantly, airports have diverted from a traditional model (i.e. functioning merely as an infrastructure for serving airlines) to a commercial model (i.e. generating revenue, largely via nonaeronautical business such as in-terminal shops and restaurants, parking, and car rentals) (e.g. 
Gillen, 2011; Francis et al., 2004). Passengers flying with LCCs have different purchase behaviours from those flying with FSCs (Castillo-Manzano, 2010; Lei and Papatheodorou, 2010). For example, though LCC passengers purchase foods and beverages (Graham, 2009, 2008), speciality retail stores make most of their revenue from FSC passengers (Appold and Kasarda, 2006). This variation demonstrates the need for specific, targeted services, products, and facilities for each "class" of passengers within terminals. Combining the two aims in one airport makes customer satisfaction and profitability difficult (if not impossible) to achieve.

In line with the differences between LCC and FSC requirements, De Neufville (2008) makes a distinction between the airports that position themselves towards contracting with each of these two carrier types. He calls those airports focusing on LCCs "low-cost airports," and those that mainly serve FSCs "legacy airports." Low-cost airports are planned, managed, and developed very differently from legacy airports, and their respective business models differ accordingly (De Neufville, 2008). The conflicts arising from these distinct requirements makes the congruence of the two models non-optimal. Thus, we conclude the following:

Hypothesis 1. There is a curvilinear (U-shape) relationship between the strategic purity of an airport and its financial performance; the higher the airport's orientation to either low-cost or full-service carriers, the higher its performance.

As the environment becomes more competitive, applying an effective strategy becomes even more crucial for gaining competitive advantage. We know from Hotelling's model (1929), and its later expansion by Ferreira and Thisse (1996), that nearby firms try to differentiate (vertically) from each other and serve a particular segment of the market; otherwise, they will go through a price war which eventually drains their profits (Fröhlich and Niemeier, 2011). Hence, in 
cases of neighbouring airports, which compete for passengers more profoundly than with other distant airports, we expect a clear strategic positioning of the airports: one airport will mainly serve FSCs and the other LCCs. In fact, several examples (e.g. airports within or close to London, Berlin, Paris, New York, and Rome) confirm this prediction (Fröhlich and Niemeier, 2011).

As noted, one of the main benefits of pure strategies is that they protect the firm from rivals' attacks on two fronts (Miles and Snow, 1978; Shinkle et al., 2013; Thornhill and White, 2007); hybrid strategies are exposed to competition from both low-cost and differentiation strategies. The more competitors (i.e. points of attacks) that exist in the market, the more vulnerable the "in-the-middle" position becomes. Therefore, the pursuit of hybrid strategies (i.e. orienting an airport to both LCCs and FSCs almost evenly) is more detrimental for the airport's performance the stiffer the competition with other (nearby) airports becomes. In a similar vein, Shinkle and co-authors (2013) posit that a market-orientated institutional environment (in transition economies), which increases the entry of foreign competitors, enhances the benefit of pure strategies. Thus, we conclude:

Hypothesis 2. The curvilinear (U-shape) relationship between the strategic purity of an airport and its financial performance is more pronounced in more competitive situations; the performance benefit of the airport orientation to either low-cost or full-service carriers increases with competition intensity.

\section{Methodology}

\subsection{Data collection}

We collected longitudinal data for the 150 busiest U.S. airports from 2006 to 2017. Airports' financial data were obtained from the Federal Aviation Administration (FAA) database, one of the 
main sources in U.S. aviation studies. The FAA requires that all U.S. commercial service airports annually file their financial reports in the Compliance Activity Tracking System, Form 127, which is publicly available for download. We used the same database to determine airports' hub status and the area, in which the airports are located, from which we compute the number of airports serving the same city market, as our measure of competition intensity. The airport traffic data and data for the market share of major airlines at a given airport were obtained from the U.S. Bureau of Transportation Statistics (BTS), "Airport Snapshots" section. BTS ("Schedule P-6" in the "Air Carrier Financial" section and "Air Carrier Traffic \& Capacity T-1" in the "Air Carrier Summary Data) is also our source for the airlines' financial data, from which we build our indicator for distinguishing LCCs from FSCs. After eliminating observations with missing data about the airlines' market share, airlines' financial data, and airports' total passengers and assets, our final sample consisted of 1451 observations, associated with 150 airports for the twelve years from 2006 to 2017. We gather Gross Domestic Product (GDP) in millions of current USD, population density in person per square mile, and House Price Index (HPI) data with 2000 as the base year, all of which have been used in robustness analyses, from U.S. Bureau of Economic Analysis, Census Bureau, and Federal Housing Finance Agency, respectively.

\subsection{Variables}

Our dependent variable is airport financial performance measured by operating profit (in millions of U.S. dollars), which covers profit from all aeronautical and non-aeronautical operations. In particular, revenue obtained from airline landing fees, terminal arrival fees, land and non-terminal facility leases, in-terminal food and beverage sales, duty-free sales, parking and ground transportation, and the like subtracted from operating expenses such as personnel compensation and benefits, supplies and materials, communications and utilities, and the like. 
Our main independent variable is the strategic purity of the airports. To measure an airport's strategic purity, we must first distinguish LCCs from FSCs. Previous studies detail the challenges in accurately defining LCCs and question the dichotomous indicator of being low-cost or not (Fageda, Suau-Sanchez, and Mason, 2015), or defining LCCs by the charged ticket price (De Neufville, 2008) or the size of the airport they serve (Graham and Dennis, 2007).

Some papers have reported cost per available seat mile (CASM) as a metric that differs notably for FSCs versus LCCs (De Neufville, 2008; Gillen and Gados, 2008; Gillen and Morrison, 2003) and thus serves as a useful differentiator between the two. As Hüschelrath and Müller (2011) assert, despite disagreement about the precise definition of LCCs (e.g. lack of business class seats, type of chosen airports, level of in-flight services, etc.), the common denominator for all LCCs is, indeed, low CASM. Accordingly, we identify LCCs (or FSCs) by transportation-related expenses per available seat mile ${ }^{1}$. The lower this variable, the closer the airline is to an LCC model, and the higher it is, the more likely it is that the airline follows an FSC model. Using CASM and the market share of the five major airlines at a given airport, we compute an airport's strategic purity as follows:

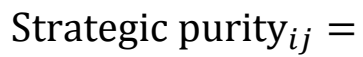

$\sum_{\mathrm{k}=1}^{\mathrm{n}}$ Cost per SeatMile $_{\mathrm{j}, \mathrm{k}} \times \mathrm{MS}_{\mathrm{ijk}} \quad$; for airport $i$ at year $j$,

where $M S_{i j k}$ is the market share (based on enplaned passengers, both arriving and departing) of the airline $k$ at year $j$ in the airport $i$. Hence, low (or high) value for the strategic purity variable indicates the airport is dominated by LCCs (or FSCs), indicating the airport's orientation towards

\footnotetext{
${ }^{1}$ Using passengers food cost per available seat mile, as an alternative measure, does not change our main results (not reported here, but available from authors upon request).
} 
pure strategies. Whereas, the airport with a value in the middle of the spectrum is one in which both types of airlines operate comparatively alike - a hybrid strategy. To reduce the skewness, the natural logarithm of this variable is incorporated into our models.

To test our second hypothesis, we use the (spatial) competition intensity among airports as the moderator variable (i.e. its interaction with our independent variable) measured by the number of airports that serve the same city market - applying the "city market id" suggested by U.S. Bureau of Transportation Statistics (BTS) to "consolidate airports serving the same city market"2 , and consistent with previous studies (e.g., De Neufville, 1995; Van Dender, 2007). The main effect of this variable has been added to the control variables set, as follows.

In addition, we include a set of control variables in our model: hub status of the airport (large, medium, small hub, or non-hub airport), the (natural logarithm of) total passengers flying to/from the airport, and (the natural logarithm of) the airport's total assets as a proxy for airport size (Bel, and Fageda, 2010; Van Dender, 2007). We also control for the airport concentrationthat is, the concentration of airlines (regarding passengers' enplanement) within each airport using the Herfindahl-Hirschman index. The higher the concentration of airlines operating within an airport, the lower that airport's bargaining power is, which can affect its financial performance. In addition, the concentration of airlines in a given airport, the higher the competition is among airlines, which reduced the ticket price and boost traffic, which again affect the airport financial performance. Finally, obtaining the data from Oum and colleagues (2006), we account for different governance and ownership structure of the airports, using dummy variables for being city-owned, county-owned, governed by the airport authority, or otherwise.

\footnotetext{
${ }^{2}$ see here https://www.transtats.bts.gov/Glossary.asp?index $=\mathrm{C}$
} 
It is worth noting that we intentionally elected not to include airport fixed effects in our models. As the number of rival airports in a city market is time invariant, by the inclusion of airport fixed effects we cannot estimate the impact of this variable. Additionally (and most importantly), incorporating airport fixed effects makes the coefficient of strategic purity statistically insignificant (the result are not reported here but available upon request). We believe the main reason for this result is that within the period of our panel data (12 years), the dominance of LCCs or FSCs (hence, our strategic purity variable) does not change substantially. The airline-airport contract tends to be a long-term one-15 to 30 years according to Sabel (2004). Therefore, the effect of strategic purity from airport fixed effects is not easily distinguishable (Van Dender, 2007).

\subsection{Model specification}

For testing the first hypothesis, we use ordinary least square (OLS) regression, as follows:

$$
\begin{gathered}
\text { Operating Profit }{ }_{i t}=\beta_{0}+\beta_{1} \text { Strategic Purity } y_{i t}+\beta_{2} \text { Strategic Purity }_{i t}^{2}+\beta_{j} X_{i t}+T_{t}+ \\
\varepsilon_{i t},
\end{gathered}
$$

where $X_{i t}$ is a vector of control variables and $T_{t}$ is the year fixed effects. As we expect to see a curvilinear (U-shaped) impact of strategic purity on operating profit, its quadratic (i.e. squared) term is added into the model. The standard errors are robust to heteroskedasticity and clustered at airport level to account for any arbitrary correlation among observations belonging to the same airport. Examining the second hypothesis, we add the competition intensity variable and its interaction with strategic purity. In this model, we evaluate the strategic purity premise at different levels of competition in the city market in which the airport operates: 
Operating Income It $_{1}=\beta_{0}+\beta_{1}$ Strategic Purity $_{i t}+\beta_{2}$ Strategic Purity $_{i t}^{2}+$

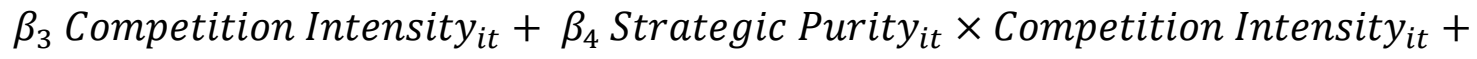
$\beta_{5}$ Strategic Purity $_{i t}^{2} \times$ Competition Intensity $i t+\beta_{j} X_{i t}+T_{t}+\varepsilon_{i t}$

As we have strategic purity, strategic purity squared, and their interactions with competition intensity, for an easier interpretation, we normalise the strategic purity variable to be always positive, before incorporating it into all models. Specifically, strategic purity is transformed to [standardised (strategic purity) +8$] / 2$.

\section{Findings}

Table 1 provides the descriptive statistics and correlations of the dependent, independent, and control variables. Strategic purity has a positive correlation with airport operating profit. Competition intensity also correlates positively with operating profit. However, one may question the competition intensity variable - measured by the number of rival airports in the same city for being endogenous. Large cities, which are more likely to be served by multiple airports, have qualitatively different demographic and economic situations than small cities, which usually have only one airport. These characteristics (e.g. higher population density, citizens' income and salary, etc.) can affect the demand for the airports and, eventually, their operating profit. In our econometric analyses, we deal with this potential endogeneity by applying a two-stage least square model, as described in section 4.

Airports with low (high) values of strategic purity are oriented towards LCCs (FSCs). For instance, Atlantic City International Airport with an average strategic purity of 1.49 is among airports that are highly oriented towards (i.e., dominated by) LCCs, while Charlotte Douglas International Airport with an average strategic purity of 4.49 is among airports on the other side 
of the spectrum, that is, FSC oriented airports. All of these airports are associated with, relatively, pure strategies, and we expect a favourable financial performance for them. Figure 1 shows the distribution of the strategic purity variable. Although the variable has been used after a natural logarithm transformation, the histogram still shows a skewness toward higher levels. We deal with this potential problem in the robustness analysis section.

**Insert Figure 1 about here**

**Insert Table 1 about here**

Table 2 reports the results of conducting our OLS model. In Model 1 only control variables are included. In Model 2, we incorporate strategic purity and strategic purity squared for testing Hypothesis 1. Model 3 contains a full set of variables, including competition intensity and its interactions, for testing Hypothesis 2.

As Model 2 depicts, the linear term of strategic purity is negative and statistically significant $(\beta=-43.54, p$-value $<0.05)$, its square term is positive and significant $(\beta=6.65, p$ value $<0.05$ ). Hence, the functional form of operating profit in terms of strategic purity depicts a U-shaped relationship; as strategic purity increases, the operating profit decreases up to a certain point, after which it rises monotonically.

In Figure 2, using the estimated coefficients for strategic purity variables (all else equal), we plot the fitted value of operating profit. In line with the above explanation, we can see the Ushaped relationship between strategic purity and financial performance of the airport within our sample range, which supports our first hypothesis: for both high and low values of strategic purity the operating profit will be high, while for the moderate values the operating profit is low. In other words, airport financial performance is at a maximum when the airport is dominated by either 
LCCs or FSCs, and it is at a minimum when the airport is "stuck in the middle" - that is, when both LCCs and FSCs operate in the airport at a comparatively similar level.

\section{**Insert Figure 2 about here**}

Model 3 in Table 2 shows the results with a full set of variables included. While the coefficient of strategic purity squared is negative and significant $(\beta=-23.56$, $p$-value $<0.05)$, the coefficient of its interaction with competition intensity is significantly positive $(\beta=23.876 .04$, $p$ value $<0.01$ ). This finding means that the net effect of strategic purity squared is always positive. The coefficient of strategic purity linear is positive and significant $(\beta=158.01$, $p$-value $<0.05)$, and the coefficient of its interaction with competition intensity is significantly negative $(\beta=-162.13$, p-value $<0.01)$. With an identical explanation as earlier, this pattern implies a U-shaped curve for the relationship between operating profit and strategic purity.

Moreover, higher competition intensity means a higher absolute magnitude for the positive coefficient of competition intensity interacted with strategic purity squared. Hence, the net effect of strategic purity squared is higher which implies steeper tails for the U-shaped graph ${ }^{3}$. In other words, for higher levels of competition intensity, once the airport deviates from pure strategies (i.e. approaches towards the middle point), the operating profit declines more sharply than in situations with lower levels of competition. Thus, strategic purity has a stronger effect on performance when_competition is more intensive, which supports our second hypothesis.

\section{**Insert Table 2 about here**}

\footnotetext{
${ }^{3}$ In the mathematical function of $y=\alpha \cdot x+\beta \cdot x^{2}$, for being a U-shaped curve, $\beta$ should be positive (negative $\beta$ implies an inverted U-shaped); the absolute magnitude of $\beta$ determines the steepness or flatness of the curve. Yet, the sign of $\alpha$ only determines the location of the curve in the $x-y$ surface and is irrelevant to the shape of the curve.
} 
For a more straightforward interpretation, Figure 3 plots the fitted value of operating profit for different levels of competition intensity (using the coefficients from Table 2, Model 3), all else equal. Interestingly, in the monopoly situation (where competition intensity is equal to one), the curve is almost horizontal; this means that for all degrees of strategic purity of the airport, the operating profit remains fairly constant. However, consistent with our hypotheses and the strategic purity premise, in more competitive environments, the relationship between strategic purity and operating profit is a U-shaped one.

As the number of rival airports (i.e. competition intensity) increases, the $\mathrm{U}$-shaped curve becomes steeper. In line with our second hypothesis, with more airports in a city market (i.e. more intensive competition), the financial performance gap between "stuck-in-the-middle" (hybrid strategy) airports and "pure strategy" airports (either LCC-oriented or FSC-oriented) becomes more sizable. Thus, the strategic purity premise is more pronounced in intensively competitive situations.

\section{**Insert Figure 3 about here**}

A surprising point from the above figures is the differential financial performance within the pure strategies - focusing on LCCs versus FSCs. As Figure 2 shows, airports with a focus on LCCs (i.e. lower values of strategic purity) seem to perform better than airports where FSCs are the major airlines (i.e. higher values of strategic purity) ${ }^{4}$. Although our theoretical framework only hypothesises about the performance impact of pure versus hybrid strategies, this last result could be worthwhile for more scrutiny in a different study. In non-reported results, we have checked and

\footnotetext{
${ }^{4} \mathrm{We}$ are grateful to an anonymous reviewer for drawing our attention to this point.
} 
found out that these differences in performance between FSC-oriented airports and LCC-oriented airports are not statistically significant.

\section{Robustness analysis}

As noted, our OLS model may suffer from endogeneity of the competition intensity variable. Larger cities, which tend to be served by more than one airport, may have specific characteristics that affect airport performance. We address this issue by estimating a two-stage least square (2SLS) model using instrument variables, which are correlated with our endogenous variables but uncorrelated with the error term (Greene, 2008). In fact, Fröhlich and Niemeier (2011) mention population size (along with income level) among the essential factors that determine the number of airports in a region. Accordingly, we run a 2SLS model, using (the natural logarithm of) gross domestic product (GDP), house price index (HPI), and (the natural logarithm of) population density of the metropolitan area in which the airport is located as instrumental variables for competition intensity. These variables correlate with the number of airports located in a given city market; yet, as city aggregate variables, they are not supposedly correlated with the error term in our airport-level model (i.e. unobserved attributes of each airport). By the same logic, the interactions between competition intensity and strategic purity (both liner and quadratic term) are also instrumented by the interactions of variables mentioned above with linear and quadratic forms of strategic purity.

Table 3 shows the results obtained from the above 2SLS and former OSL models. The 2SLS model corroborates the results of our OLS model. In particular, in Model 2, while the coefficient of strategic purity squared is negative and significant $(\beta=-29.89$, $p$-value $<0.01)$, the coefficient of its interaction with competition intensity is positive and significant $(\beta=27.75$, $p$ value $<0.05$ ); a similar pattern to our original findings, as reported again in Model 1 for comparison. 
One can argue that our selected instrumental variables are in fact drivers of the operating profit and correlate with the error term ${ }^{5}$. Although GDP and the population density of the area, theoretically, can impact the operating profit of airport located in that area-translating to higher demand for flight—, the HPI (i.e. house price index) should not have any impact on airport profits once we control for GDP and population density. Accordingly, to deal with this potential issue, as another robustness check, we only use HPI (and its interactions with strategic purity and strategic purity squared) as instrumental variable and treat GDP and population density as additional control variables in a 2SLS model. The results are reported in Model 3 of Table 3 and qualitatively similar to those of previous models, though the strategic purity linear and its interaction with competition intensity is marginally significant. Drawing the fitted value plots using estimations from Model 2 and Model 3 leads to similar graphs as in Figure 3 (not reported here, but available from authors upon request).

\section{**Insert Table 3 about here**}

Further, we also investigate various post-estimation tests to be sure about the empirical relevance and validity of our instrumental variables. The outputs of Panel A and B in Table 4 correspond to the 2SLS Model 2 and Model 3 in Table 2, respectively. For instance, as Panel A shows, the Sanderson and Windmeijer (2016) test, a modified and improved version of Angrist and Pischke (2009) test, rejects the null hypothesis of weak- or under-identification of each of the endogenous regressors. Moreover, the joint significance of our instruments is confirmed by the Stock-Wright test. Rejecting the null hypothesis means that our instruments are not weak (Stock and Yogo, 2005; Stock and Wright, 2000).

\footnotetext{
${ }^{5} \mathrm{We}$ are grateful to an anonymous reviewer for drawing our attention to this point.
} 
In addition, the result of over-identification (Sargan-Hansen) test shows we cannot reject the null hypothesis for the Hansen $\mathbf{J}$ statistic, which indicates the validity of our instruments (i.e. no correlation with the error term). The test assumes that one instrument is valid and then tests for the validity of all other instruments (i.e. whether the instruments are uncorrelated with the error term in the second stage). Finally, both Durbin and Wu-Hausman score tests reject that competition intensity and its interaction terms with strategic purity linear and squared term are exogenous, as we predicted. All tests (in Panel B) are also supportive of our 2SLS Model 3 in Table 2. It should be noted that the Hansen $\mathbf{J}$ shows the model is exactly identified, as the number of instrumental variables is equal to the number of endogenous regressors.

**Insert Table 4 about here ${ }^{* *}$

Finally, we run an OLS model with all HPI, GDP, and population density as control variables to make sure that any omitted variable bias does not drive our original results. As Model 4 in Table 3 shows, the results corroborate our previous findings. However, one should be cautious in interpreting these results, since in these last regressions the potential endogeneity of competition intensity has not been dealt with ${ }^{6}$.

\section{Conclusions}

\footnotetext{
${ }^{6}$ In order to test the robustness of our findings to possible outliers' effects and violation of the normality assumption, first, we run our OLS model while computing the standard error by a bootstrapping method, which without assuming any specific distribution bases its estimations on the empirical distribution obtained from the re-sampling iteration. Bootstrapped standard errors are asymptotically more accurate than the ones derived from the normality assumption (Greene, 2008). Second, we apply a median regression, which is more resistant to the influence of outliers (Koenker and Bassett, 1978; Koenker and Quantile, 2005). The results derived from both bootstrapping and median regression (available upon request) are qualitatively the same as before, which lends additional support to our findings.
} 
We find that in the context of the U.S. airport industry, pure competitive strategies outperform the hybrid ones; contracting mainly with either legacy airlines or mainly with low-cost carriers yields better financial performance for an airport than mixing the two aims. The underpinning reason for this result, we argue, is the conflicting requirements for dealing with low-cost versus full-service (or legacy) airlines. Attracting these different types of airlines (and their associated passengers) necessitates particular kinds of investment, infrastructure, and pricing schemes, making it ineffective to conduct them simultaneously. In line with the strategic purity premise, the optimal strategy is to position the airport to serve either low-cost or legacy airlines, rather than leaving it "stuck in the middle."

We also find that the financial benefit of strategic purity increases as competition becomes stiffer, as it does in multi-airport cities. Interestingly, in a monopoly situation, the choice of strategy barely affects airports' profits. That is, being anywhere on the pure or hybrid strategy spectrum does not have a significant impact on an airport's profit — the curve is almost horizontal (see Figure 3). However, in all cities with more than one airport, first, the curve is U-shaped, in accordance with the strategic purity premise; and second, we see a clear steepness in the tails of the curves as the number of airports in the multi-airport cities increases (i.e. as competition increases).

Further, we introduce a continuous measure for distinguishing between low-cost and differentiation strategies, based on airports' orientation towards LCCs versus FSCs. By going beyond the dichotomous measure of pure versus hybrid that is applied by the majority of previous studies (see Thornhill and White [2007] and Manev et al. [2015] for two rare exceptions), our paper contributes empirically to the extant literature. This refined measure "enables us to examine 
relative strategy emphasis and thereby evaluate the stuck-in-the-middle hypothesis more directly than has been possible with prior operationalisations" (Thornhill and White, 2007: 554).

Like any study, our work is not without limitations. First, some of the arguments that we use to defend the advantages of strategic purity could be alleviated if the (large) airports can use different terminals for different types of airlines (i.e. LCCs or FSCs) ${ }^{7}$. Yet, our theoretical argument is not only based on the different terminal requirements for LCCs versus FSCs. As we have explained in section 2.3, airports that have different terminals have the same landing tracks; this means that from a regulatory perspective it looks hard to justify why landing fees should depend on which terminal the airline uses. Moreover, local transportation to the city is the same across terminals, and FSC passengers may have different local transportation need than LCC passenger. Therefore, we believe, being flexible regarding the terminal does not fully overcome the problems inherited to the hybrid strategies. Nevertheless, having detailed data about airports terminals specialization into different types of airlines could enrich our analyses, and it should be the subject of future research.

Another expansion of our study could involve measuring competition intensity differently than we do. For instance, one can go beyond the spatial competition by considering competition for destinations or for connecting passengers, where even airports with no nearby rivals compete with distant airports (Fröhlich and Niemeier, 2011). Second, despite being state owned, U.S. airports are privately operated, and their operations are highly contracted out to private third parties (Gillen, 2011; Gillen and Morrison, 2003). Pressure from these private firms-as well as FAA requirements for being as self-sustaining as possible — means that profitability is the core (though

\footnotetext{
${ }^{7}$ We are grateful to an anonymous reviewer for drawing our attention to this point.
} 
maybe not the only) objective for any U.S. airport (Carney and Mew, 2003). Nevertheless, our study could be expanded to other institutional environments, with different levels of privatisation and regulation (Adler and Liebert, 2014), such as fully privatised airports in the United Kingdom (Littlechild, 2018). Moreover, as mentioned earlier, our empirical findings show an apparent difference in operating profit between FSC-oriented and LCC-oriented airports. Although this difference within pure strategies is beyond the scope of our hypotheses (i.e., the difference between pure and hybrid strategies), it is worthwhile to be investigated at length. Finally, our sample skewed towards cities with only one airport. Expanding the sample to cover other areas, such as Canada or Europe, could be one solution that incorporates more non-monopoly situations. We hope that these limitations and suggestions will inspire others to initiate further research in this regard.

\section{References}

Abda, M.B., Belobaba, P.P. and Swelbar, W.S., 2012. Impacts of LCC growth on domestic traffic and fares at largest US airports. Journal of Air Transport Management, 18(1), 21-25.

Adler, N. and Liebert, V., 2014. Joint impact of competition, ownership form and economic regulation on airport performance and pricing. Transportation Research Part A: Policy and Practice, 64, 92-109.

Allen, R.S. and Helms, M.M., 2006. Linking strategic practices and organizational performance to Porter's generic strategies. Business Process Management Journal, 12(4), 433-454.

Angrist, J.D. and Pischke, J.S., 2009. Mostly harmless econometrics: An empiricist's companion. Princeton university press: Princeton, NJ

Appold, S.J. and Kasarda, J.D., 2006. The appropriate scale of US airport retail activities. Journal of Air Transport Management, 12(6), 277-287.Barrett, S.D., 2000. Airport competition in the deregulated European aviation market. Journal of Air Transport Management, 6(1), 13-27.

Barrett, S.D., 2000. Airport competition in the deregulated European aviation market. Journal of Air Transport Management, 6(1): 13-27.Barrett, S.D., 2004. How do the demands for airport services differ between full-service carriers and low-cost carriers?. Journal of Air Transport Management, 10(1), 33-39. 
Bel, G. and Fageda, X., 2010. Privatization, regulation and airport pricing: an empirical analysis for Europe. Journal of Regulatory Economics, 37(2), 142-161.

Campbell-Hunt, C., 2000. What have we learned about generic competitive strategy? A metaanalysis. Strategic Management Journal, 127-154.

Carney, M. and Mew, K., 2003. Airport governance reform: a strategic management perspective. Journal of Air Transport Management, 9(4), 221-232.

Castillo-Manzano, J.I., 2010. Determinants of commercial revenues at airports: Lessons learned from Spanish regional airports. Tourism Management, 31(6), 788-796.

De Neufville, R., 1995. Management of multi-airport systems. Journal of Air Transport Management, 2(2), 99-110.

De Neufville, R., 2008. Low-cost airports for low-cost airlines: flexible design to manage the risks. Transportation planning and Technology, 31(1), 35-68.

Dess, G.G. and Davis, P.S., 1984. Porter's (1980) generic strategies as determinants of strategic group membership and organizational performance. Academy of Management journal, 27(3), 467488.

Dobruszkes, F., 2006. An analysis of European low-cost airlines and their networks. Journal of Transport Geography, 14(4), 249-264.

Dobruszkes, F., Givoni, M. and Vowles, T., 2017. Hello major airports, goodbye regional airports? Recent changes in European and US low-cost airline airport choice. Journal of Air Transport Management, 59, 50-62.

Fageda, X., Suau-Sanchez, P. and Mason, K.J., 2015. The evolving low-cost business model: Network implications of fare bundling and connecting flights in Europe. Journal of Air Transport Management, 42, 289-296.

Ferreira, R.D.S. and Thisse, J.F., 1996. Horizontal and vertical differentiation: The Launhardt model. International Journal of Industrial Organization, 14(4), 485-506.

Forsyth, P., 2006. In: Lee, D. (Ed.), Competition Policy and Antitrust. Advances in Airline Economics Airport competition: regulatory issues and policy implications, vol. 1. Elsevier: Amsterdam.

Francis, G., Humphreys, I. and Ison, S., 2004. Airports' perspectives on the growth of low-cost airlines and the remodeling of the airport-airline relationship. Tourism Management, 25(4), 507514.

Fröhlich, K. and Niemeier, H.M., 2011. The importance of spatial economics for assessing airport competition. Journal of Air Transport Management, 17(1), 44-48.

Gillen, D., 2011. The evolution of airport ownership and governance. Journal of Air Transport Management, 17(1), 3-13. 
Gillen, D. and Gados, A., 2008. Airlines within airlines: Assessing the vulnerabilities of mixing business models. Research in Transportation Economics, 24(1), 25-35.

Gillen, D. and Lall, A., 2004. Competitive advantage of low-cost carriers: some implications for airports. Journal of Air Transport Management, 10(1), 41-50.

Gillen, D. and Morrison, W., 2003. Bundling, integration and the delivered price of air travel: are low cost carriers full service competitors?. Journal of Air Transport Management, 9(1), 15-23.

Gopalakrishna, P. and Subramanian, R., 2001. Revisiting the pure versus hybrid dilemma: Porter's generic strategies in a developing economy. Journal of Global Marketing, 15(2), 61-79.

Graham, A., 2008. Managing Airports: An International Perspective. Butterworth HeinemannElsevier: Oxford, UK.

Graham, A., 2013. Understanding the low cost carrier and airport relationship: A critical analysis of the salient issues. Tourism Management, 36, 66-76.

Graham, M., 2009. Different models in different spaces or liberalized optimizations? Competitive strategies among low-cost carriers. Journal of Transport Geography, 17(4), 306-316.

Graham, A. and Dennis, N., 2007. Airport traffic and financial performance: a UK and Ireland case study. Journal of Transport Geography, 15(3), 161-171.

Greene, W.H., 2008. Econometric analysis, $5^{\text {th }}$ Ed., Upper Saddle River: Princeton, NJ.

Hambrick, D.C., 1981. Strategic awareness within top management teams. Strategic Management Journal, 2(3), 263-279.

Hambrick, D.C., 1982. Environmental scanning and organizational strategy. Strategic Management Journal, 3(2), 159-174.

Hawes, J.M. and Crittenden, W.F., 1984. A taxonomy of competitive retailing strategies. Strategic Management Journal, 5(3), 275-287.

Hill, C.W., 1988. Differentiation versus low cost or differentiation and low cost: a contingency framework. Academy of Management Review, 13(3), 401-412.

Hotelling, H., 1929. Stability in competition. Economic Journal, 39, 41-57.

Humphreys, I., Ison, S. and Francis, G., 2006. A review of the airport-low cost airline relationship. Review of Network Economics, 5(4).

Hüschelrath, K. and Müller, K., 2011. Low cost carriers and the evolution of the US airline industry. ZEW Discussion Papers (No. 11-051): Berlin.

Koenker, R., 2005. Quantile Regression. Cambridge University Press: Cambridge, UK.

Koenker, R. and Bassett, G., 1978. Regression quantiles. Econometrica, 46, 33-50. 
Lei, Z. and Papatheodorou, A., 2010. Measuring the effect of low-cost carriers on regional airports' commercial revenue. Research in Transportation Economics, 26(1), 37-43.

Littlechild, S., 2018. Economic regulation of privatised airports: Some lessons from UK experience. Transportation Research Part A: Policy and Practice, forthcoming.

Manev, I.M., Manolova, T.S., Harkins, J.A. and Gyoshev, B.S., 2015. Are pure or hybrid strategies right for new ventures in transition economies?. International Small Business Journal, 33(8), 951973.

Miles, R.E., Snow, C.C., Meyer, A.D. and Coleman Jr, H.J., 1978. Organizational strategy, structure, and process. Academy of Management Review, 3(3), 546-562.

Murray, A.I., 1988. A contingency view of Porter's "generic strategies". Academy of Management Review, 13(3), 390-400.

Oum, T.H., Adler, N. and Yu, C., 2006. Privatization, corporatization, ownership forms and their effects on the performance of the world's major airports. Journal of Air Transport Management, 12(3), 109-121.

Parnell, J.A., 1997. New evidence in the generic strategy and business performance debate: A research note. British Journal of Management, 8(2), 175-181.

Parnell, J.A., 2006. Generic strategies after two decades: a reconceptualization of competitive strategy. Management Decision, 44(8), 1139-1154.

Pels, E., Nijkamp, P. and Rietveld, P., 2003. Access to and competition between airports: a case study for the San Francisco Bay area. Transportation Research Part A: Policy and Practice, 37(1), 71-83.

Pitt, M.R. and Brown, A.W., 2001. Developing a strategic direction for airports to enable the provision of services to both network and low-fare carriers. Facilities, 19(1/2), 52-60.

Porter, M.E. 1980. Competitive strategy, Free Press, New York, NY.

Porter, M.E., 1985. Competitive advantage creating and sustaining superior performance, Free Press: New York, NY.

Proff, H., 2000. Hybrid strategies as a strategic challenge - the case of the German automotive industry. Omega, 28(5), 541-553.

Sabel, J., 2004. Airline-Airport Facilities Agreements: An Overview. Journal of Air Law and Commerce, 69(4), p.769.

Salavou, H.E., 2015. Competitive strategies and their shift to the future. European Business Review, 27(1), 80-99.

Salavou, H.E. and Halikias, J., 2009. Strategy types of exporting firms: A view on the basis of competitive advantage. European Business Review, 21(2), 144-158. 
Sanderson, E. and Windmeijer, F., 2016. A weak instrument F-test in linear IV models with multiple endogenous variables. Journal of Econometrics, 190(2), 212-221.

Shinkle, G.A., Kriauciunas, A.P. and Hundley, G., 2013. Why pure strategies may be wrong for transition economy firms. Strategic Management Journal, 34(10), 1244-1254.

Starkie, D., 2002. Airport regulation and competition. Journal of Air Transport Management, 8(1), 63-72.

Stock JH, Yogo M. 2005. Testing for weak instruments in linear IV regression. In Identification and Inference for Econometric Models: Essays in Honor of Thomas Rothenberg, Andrews DWK, Stock JH (eds). Cambridge University Press: New York.

Stock, J.H. and Wright, J.H., 2000. GMM with weak identification. Econometrica, 68(5), 10551096.

Thornhill, S. and White, R.E., 2007. Strategic purity: A multi-industry evaluation of pure vs. hybrid business strategies. Strategic Management Journal, 28(5), 553-561.

Wiersema, F. and Treacy, M., 1995. The Discipline of Market Leaders. Addison-Wesley: Reading, MA.

Van Dender, K., 2007. Determinants of fares and operating revenues at US airports. Journal of Urban Economics, 62(2), 317-336.

Wright, P., 1987. A refinement of Porter's strategies. Strategic Management Journal, 8(1), 93101.

Zuidberg, J., 2017. Exploring the determinants for airport profitability: Traffic characteristics, lowcost carriers, seasonality and cost efficiency. Transportation Research Part A: Policy and Practice, 101, 61-72. 


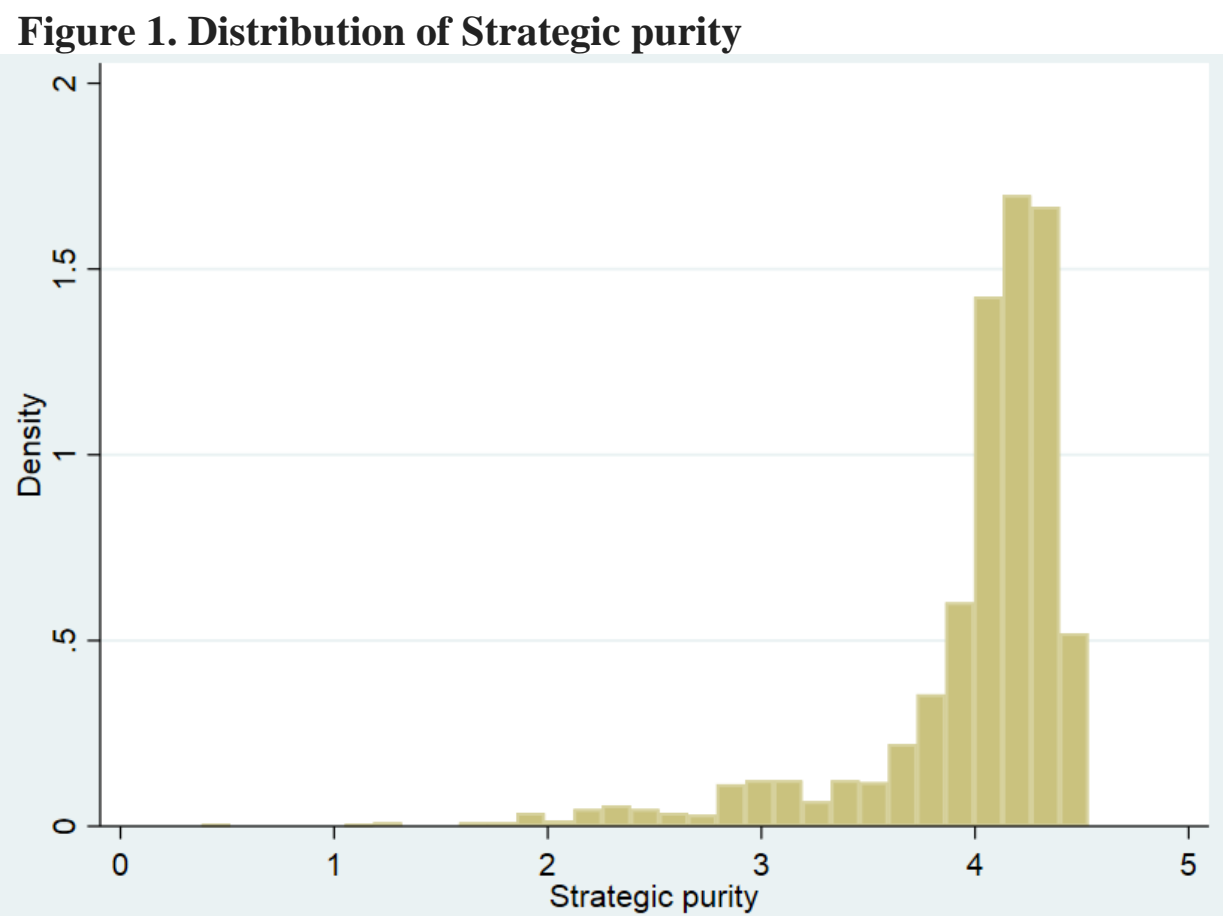

Low (high) values for strategic purity correspond to LCC-focused (FSC-focused) airports.

Figure 2. Fitted value for operating profit 


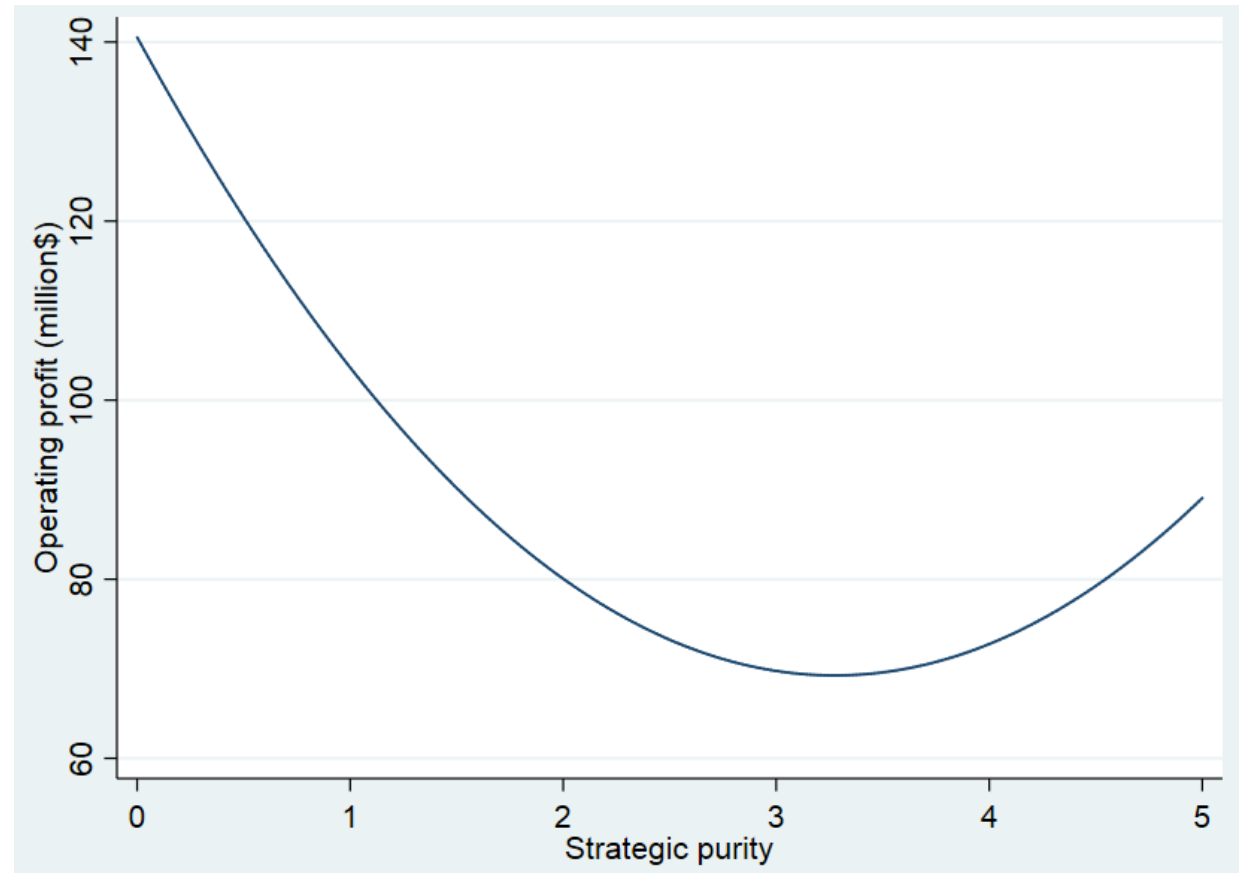

The coefficients estimation in Table 2, Model 2 is used for computing the fitted values. Low (high) values for strategic purity correspond to LCC-focused (FSC-focused) airports; a pure strategy. Medium values for values for strategic purity correspond to hybrid strategies.

Figure 3. Fitted value for operating profit at different levels of competition intensity

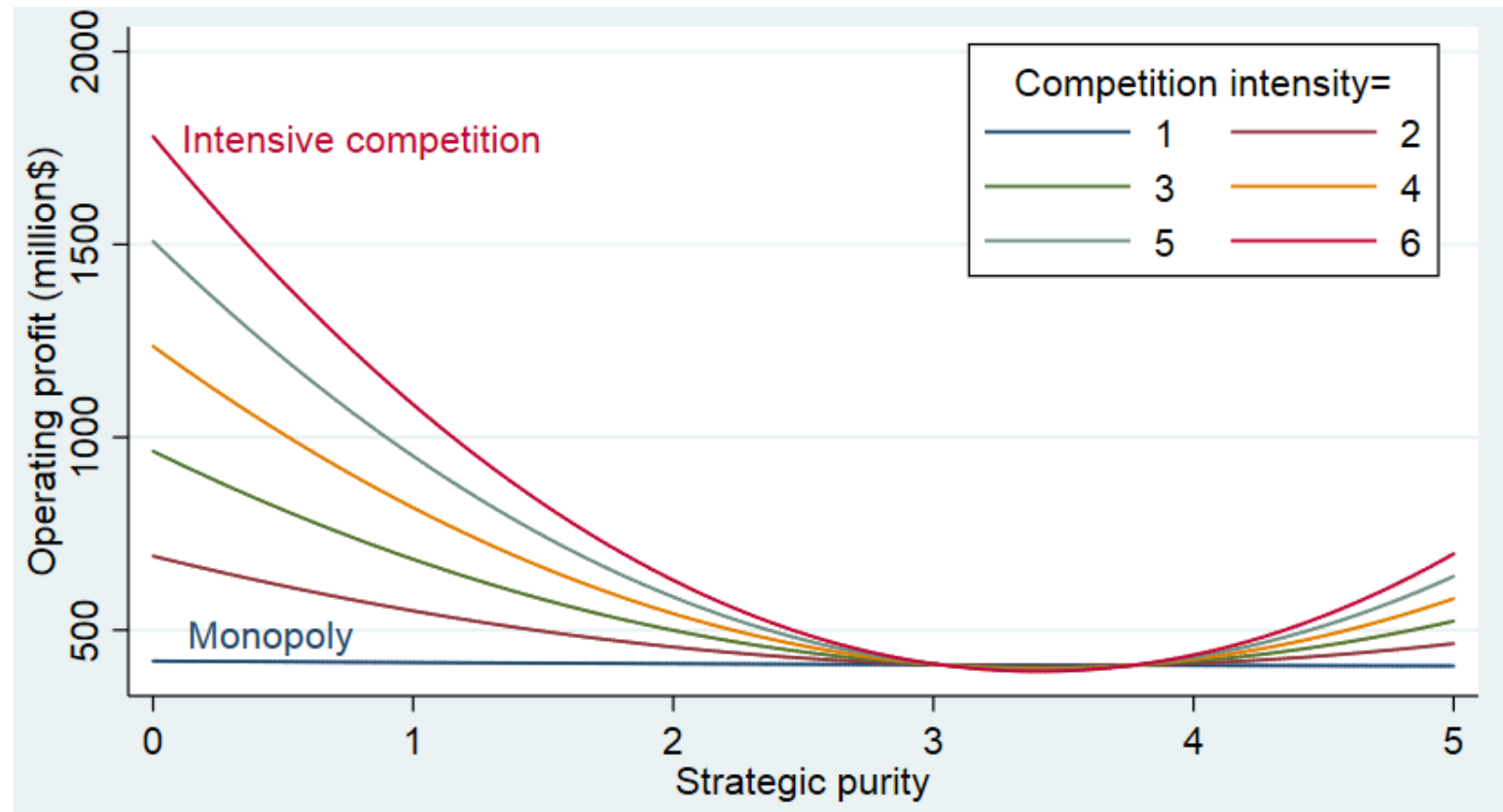

The coefficients estimation in Table 2, Model 3 is used for computing the fitted values. Low (high) values for strategic purity correspond to LCC-focused (FSC-focused) airports; a pure strategy. Medium values for values for strategic purity correspond to hybrid strategies. 
Table 1. Correlation matrix and descriptive statistics

Panel A

\begin{tabular}{llllll}
\hline Variable & $\mathrm{N}$ & Mean & Std. Dev. & Min & Max \\
\hline Operating profit & 1451 & 12.78 & 44.63 & -109.49 & 318.43 \\
Strategic purity & 1451 & 3.99 & 0.51 & 0.38 & 4.53 \\
Competition intensity & 1451 & 1.56 & 1.16 & 1.00 & 6.00 \\
Airport concentration & 1451 & 0.25 & 0.18 & 0.04 & 0.98 \\
Ln(total passengers) & 1451 & 8.31 & 1.33 & 5.53 & 11.41 \\
Ln(total asset) & 1451 & 19.79 & 1.52 & 10.75 & 23.03 \\
\hline Ln (GDP) & 1406 & 11.14 & 1.30 & 8.50 & 14.32 \\
HPI & 1434 & 144.87 & 30.59 & 70.69 & 260.46 \\
Ln(Population density) & 1434 & 5.91 & 1.07 & 2.43 & 8.02 \\
\hline
\end{tabular}

\section{Panel B}

\begin{tabular}{lllllllll}
\hline Variable & 1 & 2 & 3 & 4 & 5 & 6 & 7 & 8 \\
\hline 1.Operating profit & $\mathbf{1 . 0 0}$ & & & & & & & \\
2.Strategic purity & $\mathbf{0 . 2 1}$ & & & & & & & \\
3.Competition intensity & $\mathbf{0 . 2 6}$ & 0.02 & & & & & & \\
4.Airport concentration & $\mathbf{- 0 . 0 5}$ & $\mathbf{- 0 . 2 9}$ & $\mathbf{0 . 2 7}$ & & & & & \\
5.Ln(total passengers) & $\mathbf{0 . 4 4}$ & $\mathbf{0 . 5 1}$ & $\mathbf{0 . 2 5}$ & 0.04 & & & & \\
6.Ln(total asset) & $\mathbf{0 . 4 0}$ & $\mathbf{0 . 4 3}$ & 0.05 & $\mathbf{- 0 . 0 7}$ & $\mathbf{0 . 8 1}$ & & & \\
\hline
\end{tabular}




\begin{tabular}{lllllllll}
\hline 7. $\operatorname{Ln}(G D P)$ & $\mathbf{0 . 3 5}$ & $\mathbf{0 . 3 0}$ & $\mathbf{0 . 6 6}$ & $\mathbf{0 . 2 4}$ & $\mathbf{0 . 7 4}$ & $\mathbf{0 . 5 3}$ & & \\
8.HPI & $\mathbf{0 . 2 3}$ & 0.01 & $\mathbf{0 . 3 6}$ & $\mathbf{0 . 1 1}$ & $\mathbf{0 . 0 8}$ & 0.01 & $\mathbf{0 . 2 3}$ & \\
9. Ln(Population density) & $\mathbf{0 . 2 7}$ & $\mathbf{0 . 1 8}$ & $\mathbf{0 . 5 8}$ & $\mathbf{0 . 1 7}$ & $\mathbf{0 . 5 2}$ & $\mathbf{0 . 3 6}$ & $\mathbf{0 . 7 5}$ & $\mathbf{0 . 1 7}$ \\
\hline
\end{tabular}

All correlations with bold font are significant at the 0.05 level or better. $\mathrm{N}=1406$

Table 2. OLS regression for operating profit

\begin{tabular}{lccc}
\hline Variables & Model 3 & Model 2 & Model 1 \\
\hline Strategic purity & $158.01^{*}$ & $-43.54^{*}$ & \\
& $(64.11)$ & $(20.98)$ & \\
Strategic purity^2 & $-23.56^{*}$ & $6.65^{*}$ & \\
& $(9.49)$ & $(3.34)$ & \\
Strategic purity $\times$ Competition intensity & $-162.13^{* *}$ & & \\
& $(58.75)$ & & \\
Strategic purity^2 $\times$ Competition intensity & $23.87^{* *}$ & & \\
& $(8.52)$ & & \\
Competition intensity & $272.03^{* *}$ & $9.42^{*}$ & $9.01^{*}$ \\
& $(99.70)$ & $(3.81)$ & $(3.78)$ \\
Airport concentration & 1.73 & -21.48 & -21.73 \\
& $(11.16)$ & $(13.59)$ & $(13.64)$ \\
Ln(total passengers) & $7.96^{*}$ & 4.02 & 4.05 \\
& $(3.44)$ & $(3.35)$ & $(3.16)$ \\
Ln(total asset) & $4.12^{*}$ & $4.95^{*}$ & $5.12^{*}$ \\
& $(2.06)$ & $(2.06)$ & $(2.13)$ \\
Hub status dummies & YES & YES & YES \\
Governance dummies & YES & YES & YES \\
Year dummies & YES & YES & YES \\
Constant & $-372.22^{* *}$ & -21.79 & $-88.94^{+}$ \\
& $(125.84)$ & $(54.15)$ & $(50.63)$ \\
\hline Observations & 1451 & 1451 & 1451 \\
$R^{2}$ & 0.44 & 0.40 & 0.40
\end{tabular}


\begin{tabular}{cccc} 
Adjusted $R^{2}$ & 0.43 & 0.39 & 0.39 \\
\hline Standard
\end{tabular}

Standard errors in parentheses, ${ }^{+} p<0.10,{ }^{*} p<0.05,{ }^{* *} p<0.01,{ }^{* * *} p<0.001$

All models are OLS regressions with clustered (by airport) robust standard errors.

Table 3. OLS and 2SLS regression for operating profit

\begin{tabular}{lcccc}
\hline & Model 1 & Model 2 & Model 3 & Model 4 \\
Variables & OLS & 2SLS & 2SLS & OLS \\
\hline Strategic purity & $158.01^{*}$ & $197.08^{*}$ & $213.44^{+}$ & $165.87^{*}$ \\
& $(64.11)$ & $(79.12)$ & $(114.68)$ & $(65.01)$ \\
Strategic purity 2 & $-23.56^{*}$ & $-29.89^{* *}$ & $-35.49^{*}$ & $-24.79^{*}$ \\
& $(9.49)$ & $(11.45)$ & $(17.55)$ & $(9.66)$ \\
Strategic purity $\times$ Competition intensity & $-162.13^{* *}$ & $-187.31^{*}$ & $-181.60^{+}$ & $-161.44^{* *}$ \\
& $(58.75)$ & $(77.15)$ & $(94.61)$ & $(59.47)$ \\
Strategic purity $2 \times$ Competition intensity & $23.87^{* *}$ & $27.75^{*}$ & $29.38^{*}$ & $23.60^{* *}$ \\
& $(8.52)$ & $(11.11)$ & $(14.16)$ & $(8.63)$ \\
Competition intensity & $272.03^{* *}$ & $309.51^{*}$ & $267.84^{+}$ & $274.76^{* *}$ \\
& $(99.70)$ & $(131.42)$ & $(157.96)$ & $(100.50)$ \\
Airport concentration & 1.73 & 5.24 & 20.89 & 1.21 \\
& $(11.16)$ & $(15.39)$ & $(22.39)$ & $(12.73)$ \\
Ln(total passengers) & $7.96^{*}$ & $10.23^{*}$ & $16.10^{*}$ & $11.41^{*}$ \\
Ln(total asset) & $(3.44)$ & $(4.10)$ & $(6.69)$ & $(4.49)$ \\
& $4.12^{*}$ & 3.85 & 3.37 & $4.67^{+}$ \\
Ln (GDP) & $(2.06)$ & $(2.55)$ & $(4.45)$ & $(2.68)$ \\
Ln(Population density) & & & -4.00 & -3.17 \\
& & & $(11.32)$ & $(3.16)$ \\
& & & -1.87 & -0.81 \\
& & & $(3.79)$ & $(2.80)$
\end{tabular}




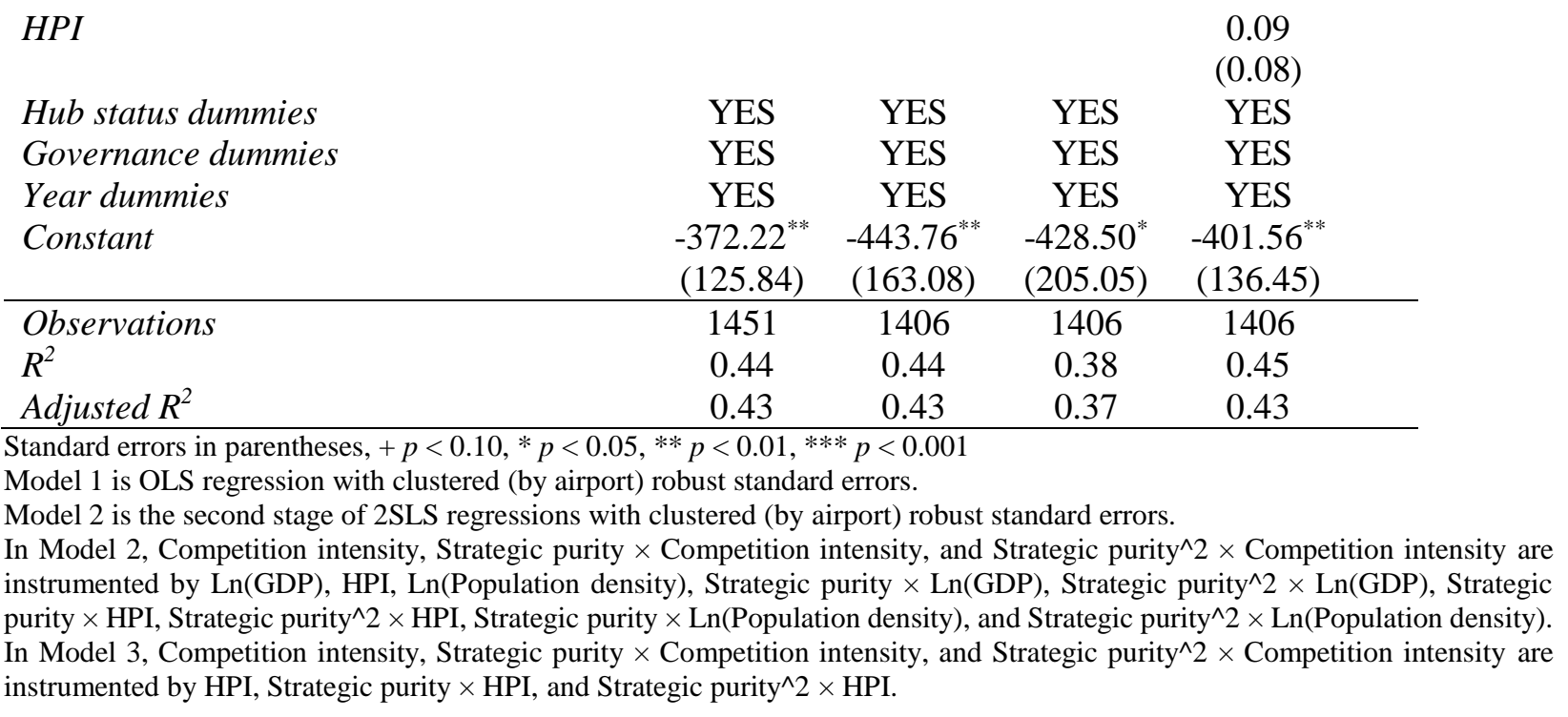

Table 4. Under-identification, weak instrument, over-identification, and exogeneity tests Panel A

\begin{tabular}{|c|c|}
\hline Instrumented Variable & $\begin{array}{l}\text { Sanderson-Windmeijer } \\
\text { under-identification test }\end{array}$ \\
\hline Competition intensity & $\begin{array}{l}\text { SW Chi-sq }(7)=75.43 \\
p=0.000\end{array}$ \\
\hline Strategic purity $\times$ Competition intensity & $\begin{array}{c}\text { SW Chi-sq(7) }=75.57 \\
\mathrm{p}=0.000\end{array}$ \\
\hline $\begin{array}{l}\text { Strategic purity } 2 \times \text { Competition } \\
\text { intensity }\end{array}$ & $\begin{array}{c}\text { SW Chi-sq }(7)=75.34 \\
\mathrm{p}=0.000\end{array}$ \\
\hline $\begin{array}{l}\text { Stock-Wright LM S statistic for joint } \\
\text { significance of endogenous regressors }\end{array}$ & Chi-square $(7)=13.66 \quad \mathrm{p}=0.05$ \\
\hline \multicolumn{2}{|c|}{ Over-identification test of all instruments $\left(\mathrm{H}_{0}\right.$ : instruments are valid) } \\
\hline \multicolumn{2}{|c|}{$\begin{array}{c}\text { Hansen J statistic: } 6.61 \\
\text { Chi-sq }(6) p=0.35\end{array}$} \\
\hline \multicolumn{2}{|c|}{ Endogeneity test for instrumented variables ( $H_{0}:$ Regressors are exogenous) } \\
\hline Durbin test & Chi-square $(3)=6.51 \mathrm{p}=0.08$ \\
\hline Wu-Hausman test & $\mathrm{F}(3,1376)=2.13 \quad \mathrm{p}=0.09$ \\
\hline
\end{tabular}

\section{Panel B}

\begin{tabular}{lcc}
\hline Instrumented Variable & $\begin{array}{c}\text { Sanderson-Windmeijer } \\
\text { under-identification test }\end{array}$ & $\begin{array}{c}\text { Sanderson-Windmeijer } \\
\text { weak-identification test }\end{array}$ \\
\hline Competition intensity & $\mathrm{SW} \mathrm{Chi-sq(1)=10.94}$ & $\mathrm{F}(1,132)=10.64$ \\
$\mathrm{p}=0.009$ & $\mathrm{p}=0.001$ \\
\hline
\end{tabular}


